\title{
Resource Recovery Potential From Lignocellulosic Feedstock Upon Lysis With Ionic Liquids
}

\author{
Beatriz Padrino ${ }^{1}$, Marta Lara-Serrano ${ }^{2}$, Silvia Morales-delaRosa ${ }^{2}$, \\ José M. Campos-Martín ${ }^{2 *}$, José Luis García Fierro ${ }^{2}$, Fernando Martínez ${ }^{1}$, \\ Juan Antonio Melero ${ }^{1}$ and Daniel Puyol ${ }^{1 *}$ \\ ${ }^{1}$ Group of Chemical and Environmental Engineering, University Rey Juan Carlos, Mostoles, Spain, ${ }^{2}$ Sustainable Energy and \\ Chemistry Group, Instituto de Catalisis y Petroleoquimica, CSIC, Madrid, Spain
}

\section{OPEN ACCESS}

Edited by:

Uwe Schröder,

Technische Universitat Braunschweig,

Germany

Reviewed by:

Vivekanand Vivekanand, Malaviya National Institute of

Technology, Jaipur, India Sreenivas Rao Ravella,

Aberystwyth University,

United Kingdom

*Correspondence:

Daniel Puyol

daniel.puyol@urjc.es

José M. Campos-Martín

j.m.campos@icp.csic.es

Specialty section:

This article was submitted to

Bioenergy and Biofuels,

a section of the journal

Frontiers in Bioengineering and

Biotechnology

Received: 13 February 2018

Accepted: 10 August 2018

Published: 05 September 2018

Citation:

Padrino B, Lara-Serrano M, Morales-delaRosa $S$,

Campos-Martín JM, Fierro JLG,

Martínez F, Melero JA and Puyol D (2018) Resource Recovery Potential From Lignocellulosic Feedstock Upon Lysis With Ionic Liquids.

Front. Bioeng. Biotechnol. 6:119.

doi: 10.3389/fbioe.2018.00119
Lignocellulosic residues from energy crops offer a high potential to recover bioproducts and biofuels that can be used as raw matter for agriculture activities within a circular economy framework. Anaerobic digestion (AD) is a well-established driver to convert these residues into energy and bioproducts. However, AD of lignocellulosic matter is slow and yields low methane potential, and therefore several pre-treatment methods have been proposed to increase the energy yield of this process. Hereby, we have assessed the pre-treatment of lignocellulosic biomass (barley straw) with the ionic liquid (IL) 1-ethyl-3-methylimidazolium acetate and its effect on the biochemical methane potential (BMP). The BMP of the residue was evaluated at different inoculum to substrate (I/S) ratios and working under meso and thermophilic conditions. Solids destruction upon $A D$ is highly enhanced by the IL-pretreatment. This also resulted in a higher BMP, both in mesophilic as well as thermophilic conditions. At the optimum I/S ratio of 2:1 (dried weight, dw), the BMP of the IL-pre-treated feedstock increased 28 and $80 \%$ for 35 days of thermophilic and mesophilic AD, respectively, as compared to the fresh feedstock, achieving values of 364 and $412 \mathrm{LCH}_{4} / \mathrm{kgTS}$. We also explored the effect of this pretreatment on the phosphorus recovery potential from the digestate upon release from the AD process. Thermophilic anaerobic digestion of IL-pre-treated biomass provided the highest $P$ recovery potential from lignocellulosic residues (close to $100 \%$ of the theoretical P content of the lignocellulosic feedstock). Therefore, the pretreatment of lignocellulosic feedstock with IL before $A D$ is a promising platform to obtain bioenergy and recover $\mathrm{P}$ to be regained for the agriculture sector.

Keywords: non-hydric lysis, circular economy, bioenergy, bioproducts, nutrients recovery

\section{INTRODUCTION}

The lignocellulosic biomass is abundant and offers a great potential for the production of liquid fuels and chemical products, which have high potential chemical energy to be transformed into biogas by anaerobic digestion (AD) (Sawatdeenarunat et al., 2015). Biogas is another energy source used as car fuel, or for production of heat or electricity in different countries (Ghosh et al., 2000; Sims, 2003). Main lignocellulosic feedstocks are energy crops and agro-forestry residues. The latter offers several advantages due to their low cost, and it does not compete with feed and food production. Moreover, high biomass yields even under low inputs of energy, water, fertilizers, and pesticides, make energy crops ideal for biogas (and bioenergy) production. 
However, the main drawback of these feedstocks is their composition, which mainly includes cellulose, hemicellulose and lignin. The interactions of these components create a highly resistant and recalcitrant biomass structure, due to many factors, like lignin content, crystallinity of cellulose, and particle size. These properties considerably decrease the digestibility of the hemicellulose and cellulose present in the lignocellulosic biomass, and in consequence the methane production rate (Mosier et al., 2005; Wilkie, 2008; Agbor et al., 2011; Zheng et al., 2014; Sawatdeenarunat et al., 2015).

In order to avoid this drawback, several pretreatments have been proposed to enhance the digestibility of lignocellulose biomass. There are several studies focused on the chemical deconstructing of lignocellulose, including thermal liquefaction, acid and alkaline hydrolysis, enzymatic hydrolysis, steam explosion, mechanical milling and ammonia fiber expansion, among others (Hendriks and Zeeman, 2009). Each pretreatment has its own effects on the cellulose, hemicellulose and lignin, the three main components of lignocellulosic biomass, and these pretreatments considerably increasing the treatment costs and the $\mathrm{C}$ footprint (Jönsson and Martín, 2016).

A promising pretreatment is the use of ionic liquids (IL) for the deconstructing of the lignocellulosic fibers, which increase the biomass volume and active surface. Ionic liquids are special solvents that can dissolve materials that are otherwise considered insoluble in conventional solvents. They consists of combinations of ions and have special properties such as broader liquid temperature, high thermal stability and negligible vapor pressure, which are the vital properties required in the transformation of lignocellulosic biomass (Galinski et al., 2006; Kassaye et al., 2017). ILs disrupt the non-covalent interactions between lignocellulose components without leading to significant degradation. ILs operation significantly decreases the temperature of the process compared to traditional hydrolytic processes (Morales-delaRosa et al., 2014a). Cellulose regenerated from IL solutions has increased enzymatic convertibility.

The pretreatment with IL favors the digestibility of the lignocellulosic biomass in a same manner than enzymatic hydrolysis, because reduce the crystallinity of cellulose and makes more accessible the cellulose chains for its transformation (Lara-Serrano et al., 2018). Some authors have tried to use IL pretreatment for the anaerobic digestion of lignocellulose (Gao et al., 2013a). These authors propose the pretreatment with a combination of IL+DMSO, which increased the methane production. However, the use of chloride IL and DMSO, can be not adequate because small quantities are toxic for the cell grow (Zhu et al., 2013), then a critical washing step is necessary to avoid this effect that cannot be applied at large scale. To avoid this drawback, the use of non-toxic solvents is mandatory to get a positive effect in the methane production. In addition, the use of these solvents for deconstructing the lignocellulosic material can release other inorganic resources, which has still not been considered and should be also exploited.

The agriculture sector is becoming compromised due to the lack of a cheap and accessible source of inorganic nutrients to sustain the increasing food demand caused by over-population, especially in developing countries (Cordell et al., 2009). Notably, phosphorus represent a key factor for the future sustainability of the agriculture, mainly due to their non-renewable origin (phosphate rock) and the specific location of the main reservoirs in few countries (Cordell et al., 2011). The efforts are being driven toward two main strategies: (a) increasing the efficiency of phosphorus assimilation by crops by minimizing the loses by percolation or runoff (Sharpley, 2016) and (b) recovering the excess of phosphorus dissipated in waste and wastewater sources by intensive recovery technologies based on a biorefinery concept (Tarayre et al., 2016). Main waste sources for P recovery origins from domestic wastewater and livestock waste (mainly manure) (Heilmann et al., 2014). Crop waste has been barely explored as a source of $\mathrm{P}$ recovery despite at least $6.4 \%$ of $\mathrm{P}$ wastage comes from post-harvested crop loses, which represents around $900 \mathrm{k}$ tons P per year worldwide (Cordell et al., 2011). Enabling a complete sustainable agriculture and reducing the pressure on the $\mathrm{P}$ extraction from high phosphate rock requires the recovery of this vast $\mathrm{P}$ source.

In this work, the pre-treatment of a lignocellulosic feedstock (barley straw) by the non-toxic ionic liquid 1ethyl-3-methylimidazolium acetate ([C2C1Im][OAc]) and in absence of other solvents was explored as a method to recover energy as biogas and phosphorus as phosphate through anaerobic digestion. Anaerobic digestion was studied at meso and thermophilic conditions, and the effect of the inoculum to substrate (I/S) ratio and the kinetics of the process was analyzed. The experimental data was used for proposing a novel platform to recover resources from lignocellulosic waste.

\section{MATERIALS AND METHODS}

\section{Materials and Chemicals}

The ionic liquid [C2C1Im][OAc] (assay $\geq 95 \%$ (HPLC)) was purchased from Sigma Aldrich and used without any further purification or treatment. The sample of lignocellulosic biomass was barley straw. This was provided and characterized by the Unit of Biofuels from the Centre of Energy, Environmental and Technological Research (CIEMAT, Madrid, Spain). It was composed of (\% in $\mathrm{dw}, \mathrm{SD}$ in brackets): extractables, 13.4 (-); aqueous, 11.0 (0.3); organics, 2.4 (0.3); cellulose, 32 (1); hemicellulose, 27.2 (0.4) [composed of xylan, 22.1 (0.5); galactane, 1.30 (0.01); arabinane + mannose, 3.87 (0.03)]; lignin acid-insoluble, 17 (1); lignin acid-soluble, 2.10 (0.03); ash, 3.89 (0.05); acetil groups, $1.72(0.02)$. The elemental composition was measured as: C (43.6\%), H (5.9\%), N (0.8\%), S (0.06\%), with a moisture of $6.1 \%$.

Mesophilic anaerobic sludge used as inoculum was collected from a full-scale anaerobic digester treating waste sludge located in a domestic wastewater treatment plant (DWWTP) (Móstoles, Spain). Thermophilic inoculum was sourced from the mesophilic inoculum, which was cultivated at $55^{\circ} \mathrm{C}$ in a lab-scale anaerobic batch reactor for more than 90 day in order to be adapted to thermophilic conditions before the extraction. The batch reactor was fed with activated sludge from the DWWTP aforementioned once per week at a rate of $1 \mathrm{~g}$ TS substrate gTS $^{-1}$ inoculum. Once adapted, the thermophilic biomass was 
collected at the end of every feed round and stored at $4^{\circ} \mathrm{C}$ before using.

\section{Ionic Liquid Pre-treatment of Lignocellulosic Waste}

The treatment of lignocellulosic biomass involved a complete dissolution of barley straw ( $3 \mathrm{~g})$ in ionic liquid $(57 \mathrm{~g})$ at $105^{\circ} \mathrm{C}$ by using a Mettler-Toledo Easy Max ${ }^{\circledR} 102$ reactor equipped with mechanical stirring. The complete dissolution was checked by direct visual observation and it happened after $7.5 \mathrm{~h}$. Thereafter, $250 \mathrm{~mL}$ of deionized water was added to precipitate the material. The solid obtained was separated by vacuum filtration with a nylon membrane (MoralesdelaRosa et al., 2014a, 2015, 2018) and it was washed with deionized water several times in order to eliminate all remaining ionic liquid. Figure 1 shows a schematic view of the process.

\section{Biochemical Methane Potential Tests}

Biochemical methane potential tests (BMPs) were conducted under meso- and thermophilic conditions (37 and $55^{\circ} \mathrm{C}$, respectively), according to (Angelidaki et al., 2009). One sixty milliliter flaks serum bottles were inoculated with anaerobic sludge and supplemented with the solid organic substrate to a $1 \%$ ds concentration. Bottles were flushed with $99.99 \% \mathrm{~N}_{2}$ gas for $1 \mathrm{~min}(4 \mathrm{~L} / \mathrm{min})$, sealed with a rubber stopper retained with an aluminum crimp seal and stored in temperature-controlled incubators for around 35 days. Tests were mixed by swirling once per day. Two blank tests containing either inoculum and no substrate or substrate and no inoculum were assessed to correct for background methane potential of the added inoculum and to know on the methanability of the substrate with no inoculum, respectively. Inoculum to substrate (I/S) ratios of 2:1, 1:1 and 1:2, expressed as total solids (TS) were tested in the BMP tests. All the tests were conducted in triplicate. All the data are averaged values with $95 \%$ confidence intervals.

\section{Analytical Methods}

Raw material and solids pre-treated barley straw were characterized at the National Renewable Energy Laboratory (NREL) using the standard methods for determination of structural carbohydrates and lignin in biomass (Sluiter et al., 2010). Moisture content was analyzed by measuring the TS and volatile solids (VS) content according to standard methods (Federation and Association, 2005). $\mathrm{NH}_{4}^{+}$and $\mathrm{PO}_{4}^{3-}$ released upon AD experiments were analyzed by Merck Kits (Merck, Kenilworth, NJ, USA) following standard procedures.

Additionally, X-ray diffractions profiles of samples were recorded with an X'Pert Pro PANalytical diffractometer equipped with a $\mathrm{CuK} \alpha$ radiation source $(\lambda=0.15418 \mathrm{~nm})$ and X'Celerator detector based on Real Time multiple Strip (RTMS). The samples were ground and placed on a stainless-steel plate. The diffraction patterns were recorded in steps over a range of Bragg (2 $\theta$ ) between $4^{\circ}$ and $90^{\circ}$, at a scanning rate of $0.02^{\circ}$ per step and an accumulation time of $50 \mathrm{~s}$. Diffractograms were analyzed with the X'Pert HighScore Plus software.

The scanning electron micrographs of fresh and pretreated barley straw with IL were taken with a Hitachi $\mathrm{S}-3000 \mathrm{~N}$ instrument. The samples were treated with increasing concentrations of ethanol to fix the structure and to dehydrate the samples. After a critical point drying with a Polaron CPD7501 critical-point drier, the samples were metallized in a Balzers SCD 004 gold-sputter coater; they were sputter-coated with a thin layer of gold.

Biogas production in the BMP tests was measured by pressure increase in the headspace by using a Mariotte oil gas meter (3B Scientific, Spain). Biogas composition was analyzed by a GC/TCD (Agilent Technologies, Santa Clara, USA).

\section{Kinetic Modeling}

Kinetic analysis was conducted by using the BMP profiles (expressed as $\mathrm{LCH}_{4} / \mathrm{kgTS}$ added). Maximum biochemical potential $\left(B_{0}, \mathrm{LCH}_{4} / \mathrm{kgTS}\right)$ and hydrolysis constant $\left(k_{H}, 1 / \mathrm{d}\right)$

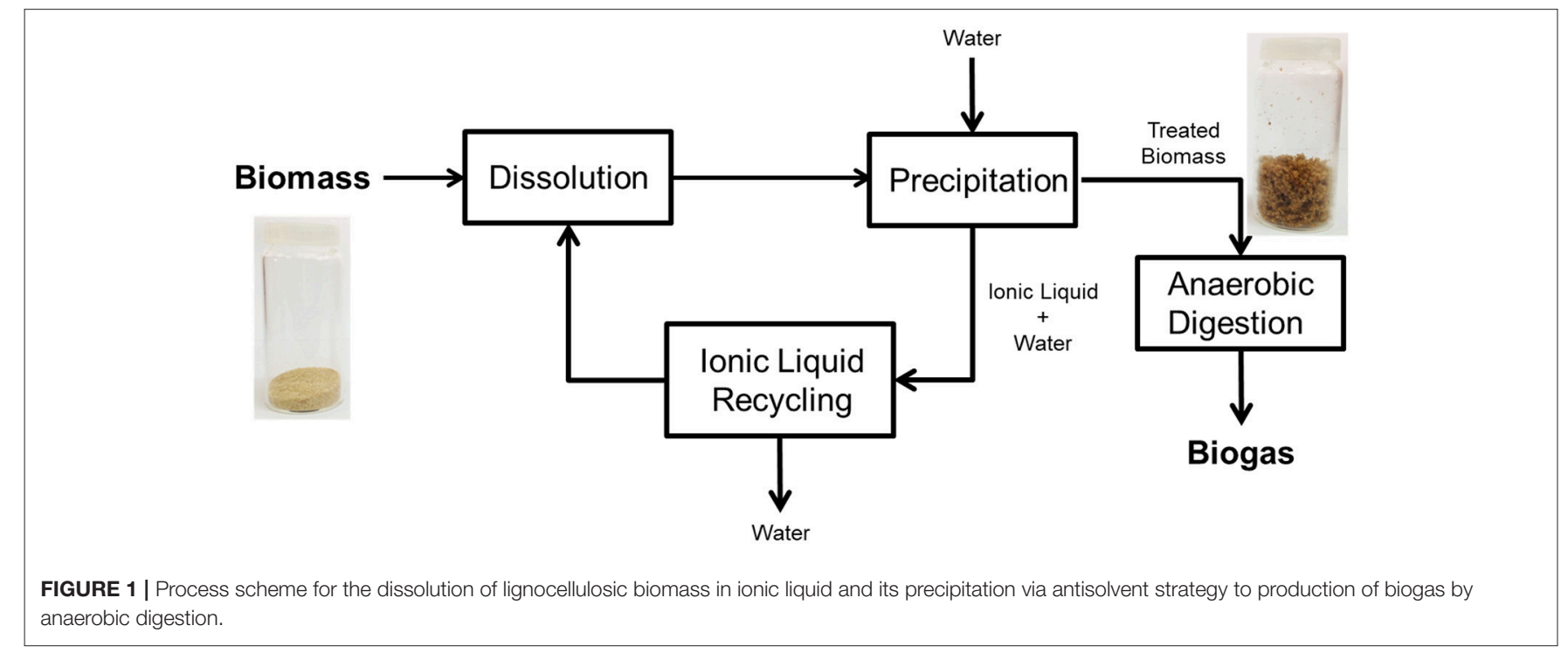


were calculated by fitting the data to a first order model. The instantaneous biochemical methane potential profiles $(B)$ can be defined as the TS fraction of the substrate that is being transformed into methane, according to:

$$
B=\frac{S_{C H_{4}}}{S}
$$

Where $\mathrm{S}_{\mathrm{CH} 4}$ is the instantaneous methane production $\left(\mathrm{LCH}_{4} / \mathrm{L}\right.$ experiment) and $S$ is the substrate concentration $(\mathrm{kgTS} / \mathrm{L}$ experiment). The process will end once all the biodegradable substrate has been transformed into methane, therefore the maximum biochemical methane potential can be defined as the maximum methane production for an infinite time of digestion $\left(B_{0}\right)$.

The model was simplified assuming no biomass growth, and can be summarized as follows:

$$
\begin{aligned}
& \frac{d S}{d t}=-k_{H} S \\
& \frac{d B}{d t}=-B_{0} \frac{d S}{d t}=k_{H} B_{0} S
\end{aligned}
$$

\section{Data Management}

Data from BMP tests are average values with 95\% confidence intervals from triplicate measurements.

Calculation of solids destruction (\%) was performed according to the Equation (4):

$$
\begin{aligned}
& \text { Solids destruction }(\%) \\
& =\left(1-\frac{\left(T S_{\text {final, } \exp }-\left(T S_{\text {initial, inoc }}-T S_{\text {final,inoc }}\right)\right)}{T S_{\text {initial, exp }}}\right) * 100
\end{aligned}
$$

Where $T S_{\text {final,exp }}$ and $T S_{\text {initial,exp }}$ are the final and initial values of the TS in the BMP of each experiment, whereas $T S_{\text {final,inoc }}$ and $T S_{\text {initial,inoc }}$ are the final and initial values of the TS in the BMP of the inoculum, respectively.

Calculation of $\mathrm{P}$ recovery potential was performed by using the following equation:

$$
\text { recovery potential }(\%)=\frac{P \text { release }\left(\frac{m g P}{g T S}\right) * 0,1(\%)}{P \text { content barley straw }(\%)} * 100
$$

Where the P content of the barley straw has been calculated from Vassilev et al. (2010) (0.148 \% dw).

The mathematical model of the BMP tests was implemented on Aquasim 2.1d. Parameter values and uncertainty analysis were simultaneously estimated, with a 95\% CI. Ninety-five percent confidence regions for parameters values were also estimated. Simulation curves were determined by using optimum parameter values. $B$ was used as a measured variable, with sum of squared errors as an objective function. All the kinetic analysis was performed as per Segura et al. (2016).

\section{RESULTS AND DISCUSSION}

\section{Ionic Liquid Pretreatment of the Barley Straw}

The dissolution of barley straw in [C2C1Im] [OAc], followed by precipitation in water (antisolvent) induced important morphological and textural changes, as already seen in previous works (Morales-delaRosa et al., 2014a, 2015, 2018). The original sample has the typical appearance of sawdust. However, the treated sample is much spongier with a greater volume (Figure 2). There is also a change of color from light to darker brown when the barley straw is treated; it must be considered that the sample is very moist. Moisture of the pre-treated biomass was measured as $89.9 \%(0.9)$.

SEM images show large differences in the morphology between the original barley straw and the treated with ionic liquid (Figure 3). After $7.5 \mathrm{~h}$, the initial structure of the barley straw has been destroyed. In Figure 3a, the lignocellulosic structure of the barley straw has been seen with the presence of its vascular bundles forming cavities along small pieces. However, that structure is lost in the treated lignocellulosic biomass (Figure 3b).

$\mathrm{X}$-ray diffraction technique is a powerful tool to analyze the crystalline nature of the materials. Figure 4 shows the comparison of XRD patterns of original barley straw and biomass pre-treated. The diffractogram of untreated barley straw shows typical peaks of the crystalline structure of cellulose, although these peaks are wider and less defined than pure cellulose. This implies the presence of a less orderly or sizes smaller crystal structure. A prominent peak at $23^{\circ}$ corresponds with reflection to (200), whereas a peak width between $15^{\circ}$ and $17^{\circ}$ represents the combination of the two reflections to (1-10) and (110) (Morales-delaRosa et al., 2014b). The intensity of the diffraction

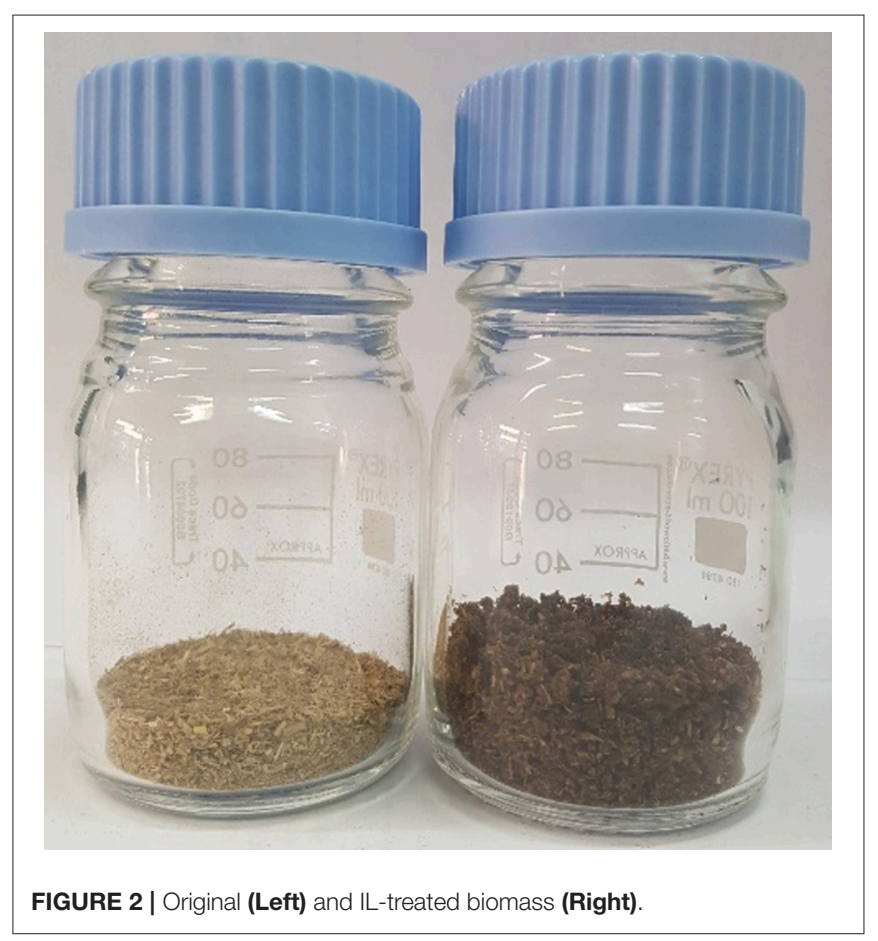



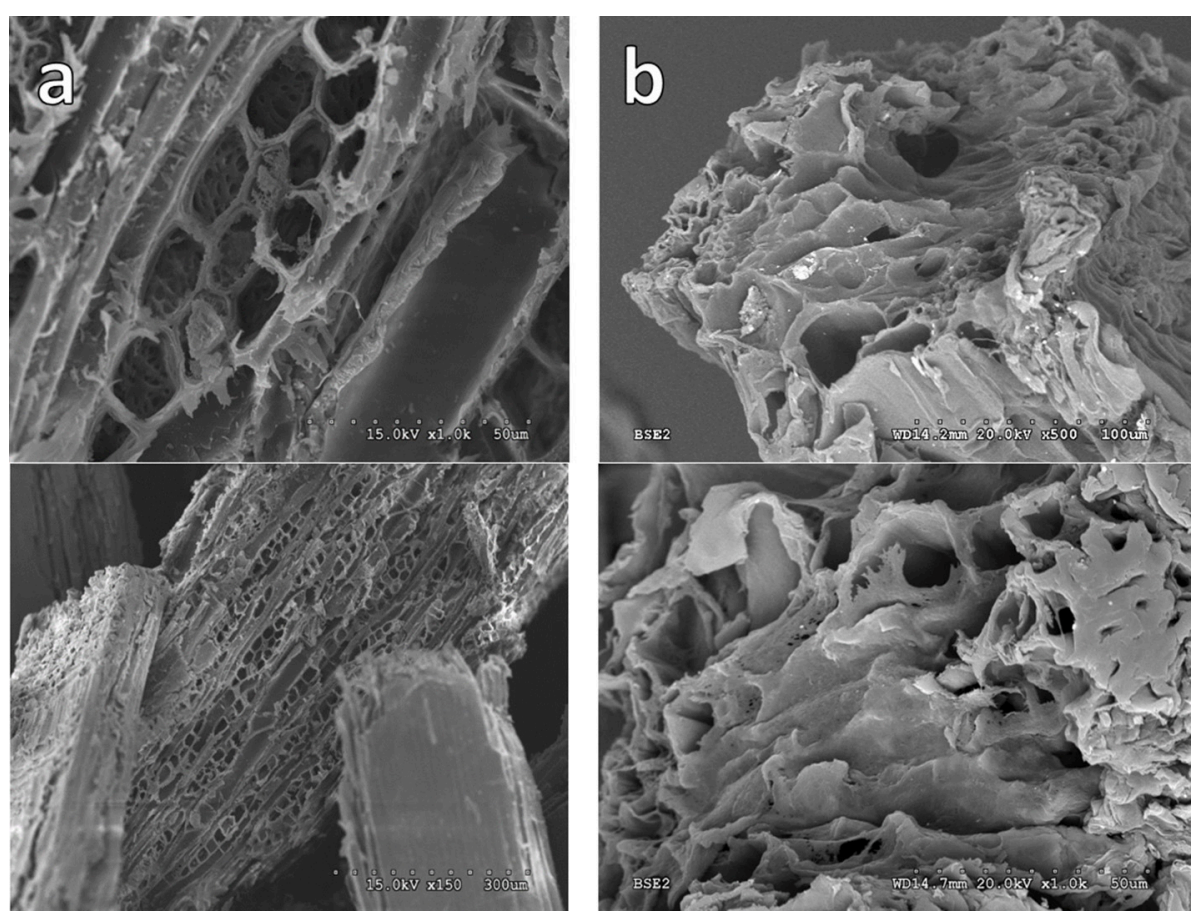

FIGURE 3 | SEM micrographs of Original Barley Straw (a) and the barley straw after treatment with IL (b). The pictures below show an enlargement of the same above. The initial structure has been missing but not completely.

peaks losses intensity with the treatment of the sample. Peaks were not observed in the diffractogram of the pre-treated sample, indicating a total disappearance of its crystallinity. This study indicates that the original barley straw has a crystallinity that is lost when treated with ILs (Cheng et al., 2011; Shi et al., 2013).

Therefore, XRD and SEM images showed the loss of crystallinity and a dramatic change in the structure and morphology of the starting material. Thus, at the end of the reconstruction process, the biomass substrate exhibited a much more accessible surface. As the biomass has lost its structure and increased this reactive surface, it was tested as a feedstock for the production of biogas by anaerobic digestion.

\section{Biochemical Methane Potential Tests}

Solids destruction upon the BMP tests (\%) was analyzed and compared between fresh and pre-treated biomass. Table 1 shows the values for thermophilic and mesophilic experiments. In general, the solids destruction is much higher (around 2-fold in almost all the cases) in the IL-pre-treated biomass experiments compared to the experiments using fresh biomass. However, there are differences between thermophilic and mesophilic conditions. The I/S ratio does not seem to affect the solids destruction values in thermophilic conditions, indicating that the digestion time is enough to achieve the maximum hydrolysis potential of the biomass even under low I/S ratios (1:2) (around 71-79\%). By contrast, the I/S ratio clearly affects the solids destruction in mesophilic conditions. Under I/S ratios of 2:1 and 1:1 the solids destruction is statistically similar in both fresh and IL-pre-treated biomass experiments (yielding 73-85\%), whereas an I/S ratio of 1:2 clearly causes a decrease of this value (down to $62 \%$ ). This is explained by lower hydrolysis rates found under mesophilic conditions (Kim et al., 2003). Therefore, it can be inferred that the pre-treatment of lignocellulosic material greatly enhances the hydrolysis of the biomass, but an excess of substrate causes a drop of the hydrolysis rate in mesophilic conditions. The latter also has important connotations on the release of organics and inorganics and the methane production, as will be furtherly discussed.

The release of carbon and nutrients upon anaerobic digestion is an important aspect of the potential resource recovery from the digestate. Table 2 shows the release of soluble COD, $\mathrm{N}$ as ammonium and $\mathrm{P}$ as phosphate, as well as the final $\mathrm{pH}$ of the process. Both ammonium and phosphate are the $\mathrm{N}$ and $\mathrm{P}$ forms that released upon anaerobic digestion, which came mainly from proteins (in the case of $\mathrm{N}$ ) and from phospholipids and nucleic acids (in the case of P) (Mehta and Batstone, 2013). The low $\mathrm{N}$ release associated to the substrate is indicative of the low $\mathrm{N}$ content of the biomass $(0.8 \% \mathrm{dw})$. Indeed, higher ammonium release is observed at increasing I/S ratios, as the $\mathrm{N}$ content of the inoculum highly exceeds the lignocellulosic substrate one. In addition, there is no clear relationship between the $\mathrm{N}$ release and the pre-treatment or the temperature conditions. P release, however, is comparable or even enhanced at low I/S ratios. This will be furtherly analyzed and detailed below, since this has high impact on P recovery potential.

Results of soluble COD (sCOD) evidenced that thermophilic conditions released much more organic compounds than mesophilic conditions. This is usually explained by the 


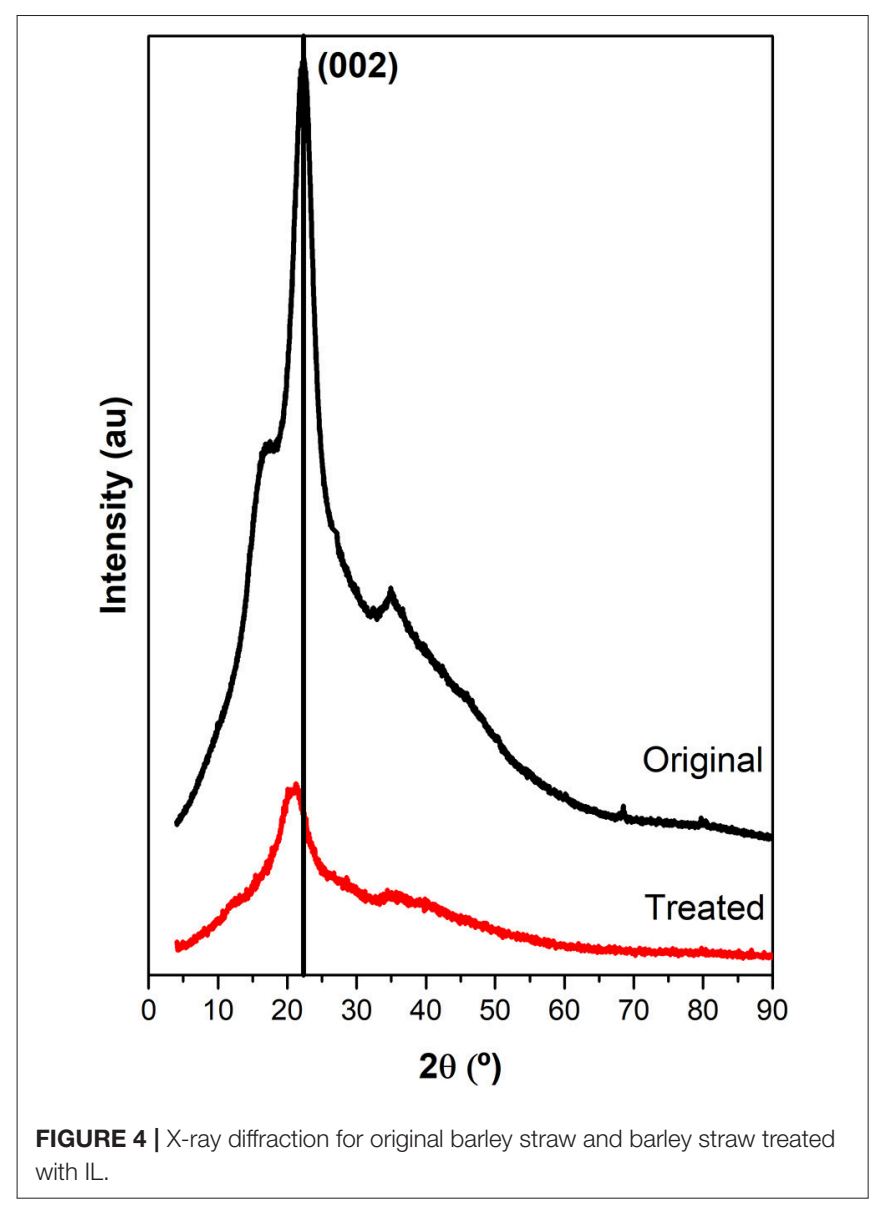

solubilization of a proportionally higher fraction of soluble inerts due to higher hydrolysis extent, but also as a result of a proton imbalance due to a fast hydrogen production (in acidogenesis steps) which favors hydrogenotrophic methanogens, which also causes accumulation of volatile fatty acids and alcohols (FrankeWhittle et al., 2014). However, there is no clear trend indicating whether the pre-treatment of the lignocellulosic biomass is favorable or not for avoiding the accumulation of soluble organics, as the trend of sCOD release in both cases is analogous. In contrast, the pre-treatment clearly enhances the biodegradability of the soluble organic matter in mesophilic conditions, as demonstrated with the significantly lower sCOD observed for the I/S ratios of 2:1 and 1:1 in the pre-treated experiments. The higher sCOD in the 1:2 I/S ratio responds to a soluble substrate accumulation due to an excess of substrate, and will be discussed with the methane production data. It can be anticipated that the $\mathrm{pH}$ is not a possible cause of inhibition since the final $\mathrm{pH}$ in all cases under mesophilic conditions is $>7$ and therefore acidification does not occur, presumably due to high alkalinity of the process.

Figure 5 depicts the biochemical methane potential profiles. Thermophilic AD of the treated barley straw showed a remarkable methane production for the initial days of the $\mathrm{AD}$ at the I/S ratio of 2:1 (Figure 5A). The pre-treated biomass achieved a methane production increase of $28 \%$ after 35 day of
TABLE 1 | Solid destruction (\%) at different I/S ratios in thermophilic and mesophilic conditions upon BMP tests.

\begin{tabular}{lcc}
\hline I/S ratio & Fresh biomass & IL-pre-treated biomass \\
\hline THERMOPHILIC & & \\
$2: 1$ & $27 \pm 9$ & $74 \pm 9$ \\
$1: 1$ & $44 \pm 9$ & $71 \pm 8$ \\
$1: 2$ & $37 \pm 8$ & $79 \pm 9$ \\
MESOPHILIC & & \\
$2: 1$ & $59 \pm 5$ & $73 \pm 7$ \\
$1: 1$ & $48 \pm 7$ & $85 \pm 9$ \\
$1: 2$ & $39 \pm 4$ & $62 \pm 6$ \\
\hline
\end{tabular}

$\mathrm{AD}$, whereas there were no significantly differences in the BMP at I/S of 1:1 and 1:2. However, the thermophilic process was faster in all cases when the fresh biomass was used. This could be attributed to the fast fermentation of the oligosaccharides due to high temperature, causing accumulation of volatile fatty acids and alcohols that inhibits the methanogenesis (Holliger et al., 2016). This may explain the higher $\mathrm{CO}_{2}$ production observed in the pre-treated experiments compared to the fresh experiments (around 2-4\% higher in all cases) and the high SCOD at the end of the BMP tests in the pre-treated biomass experiments. All these results evidence an over-activity of fermentative bacteria, which caused high impact on the methane production rate.

In contrast, the IL pre-treatment caused a considerable increase of the BMP of the biomass at mesophilic conditions. BMP increased 77,108 , and $14 \%$ for I/S of $2: 1,1: 1$, and $1: 2$, respectively (Figure 5B). The higher methane potential of the pre-treated biomass is clearly evidenced. However, a low I/S ratio also caused inhibition problems. In this case of $\mathrm{I} / \mathrm{S}$ of $1: 2$, the methanogenesis is inhibited compared to the other I/S ratios. The accumulation of SCOD is an evidence of the inhibited methanogenesis (see Table 2), which also caused a decrease of the solids destruction (see Table 1), therefore affecting also the hydrolytic bacteria. These results as a whole indicate that, in an optimized I/S ratio (or optimized substrate addition rate), the quantity of energy recovered by anaerobic digestion is around 2 -fold when the lignocellulosic biomass is pre-treated with 1ethyl-3-methylimidazolium acetate.

Results obtained in this study are comparably better than most of the few studies found about this subject in the literature (Table 3). We obtained the highest BMP value of any of the values extracted from the literature under mesophilic conditions at an I/S ratio of 2:1 (412 $\left.\mathrm{L} \mathrm{CH}_{4} / \mathrm{kgTS}\right)$, yielding an improvement of $80 \%$ with respect to the anaerobic digestion of the untreated feedstock. Most of the studies analyzed used NMethylmorpholine N-oxide (NMMO) as a solvent to dissolve the cellulose, obtaining improvements of methane production ranging from 14 to $630 \%$, though are normally around $80 \%$, irrespective of the thermal conditions of the BMP tests. However, the digestion time of these studies is considerably longer than the time used in the present study (longer than 40 vs. 35 day of this study), which would be biased the significance of the outcomes extracted (Aslanzadeh et al., 2011; Teghammar et al., 2012; Purwandari et al., 2013; Kabir et al., 2014; Mancini 
TABLE 2 | Soluble COD, N and P released upon anaerobic digestion in the BMP tests.

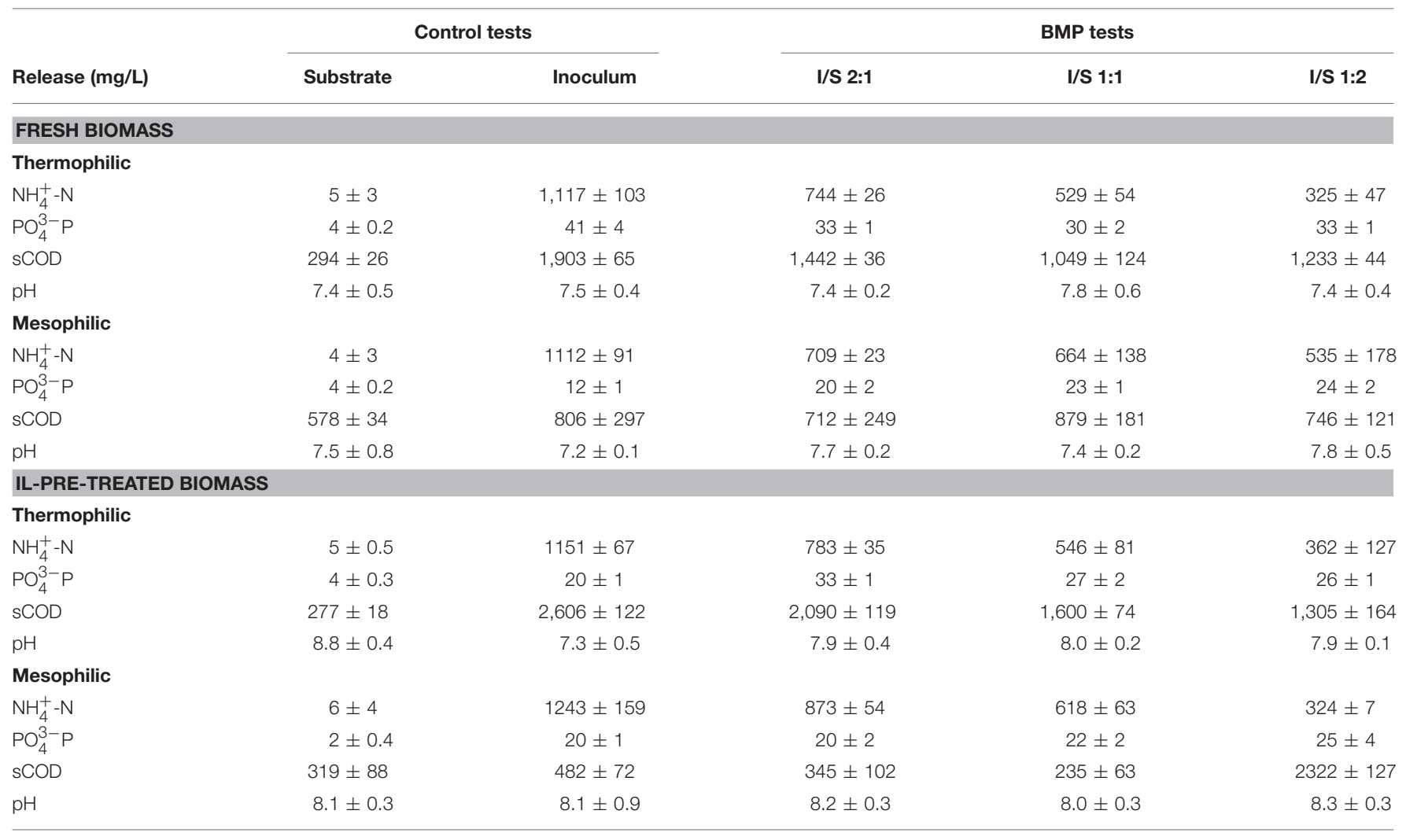
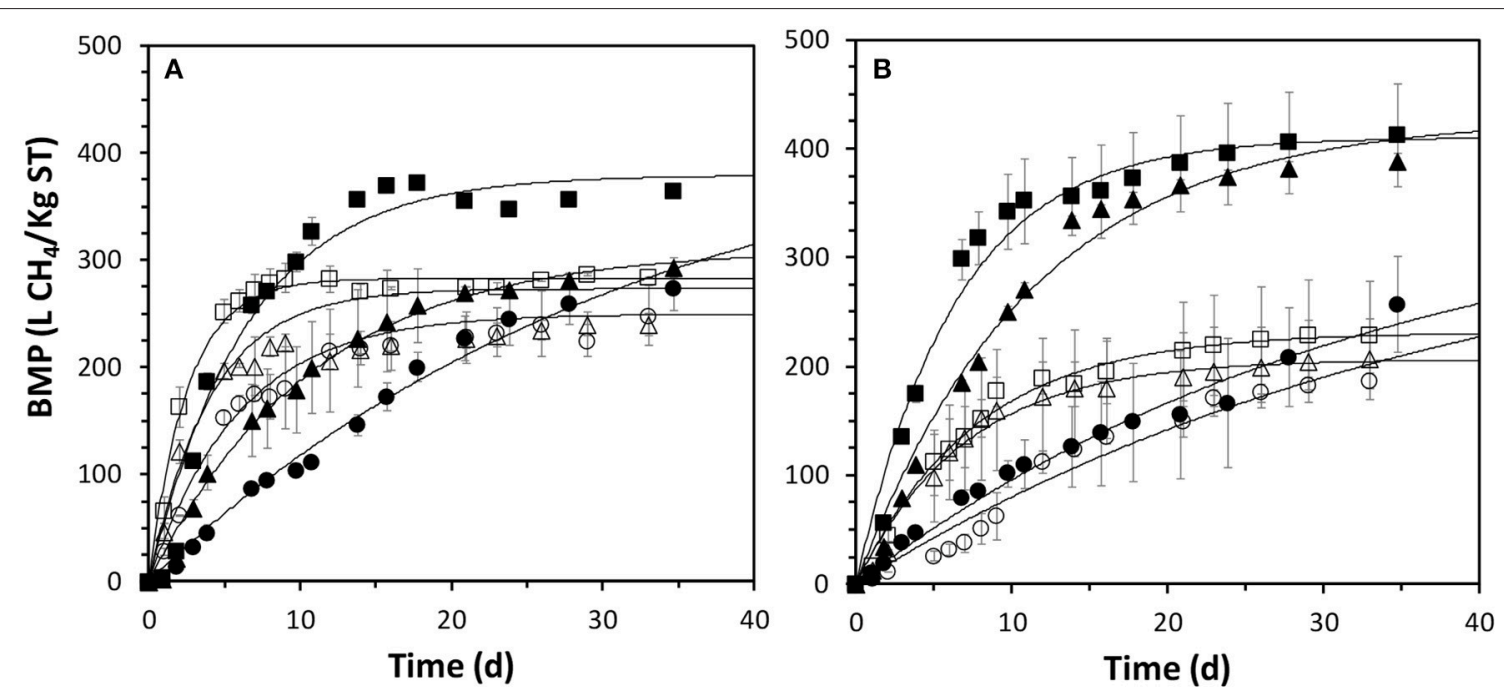

FIGURE 5 | Thermophilic (A) and mesophilic (B) BMP profiles of fresh (open symbols) and pre-treated (closed symbols) at l/S ratio of 2:1 (squares), 1:1 (triangles) and $1: 2$ (circles). Error bars are 95\% confidence intervals of average values from triplicates. Continuous lines are simulation curves.

et al., 2018). In addition, NMMO is not considered as an IL system, but a deep eutectic solvent, and therefore its recovery by precipitation with water after the treatment is not possible. Other studies used the solvent system 1-butyl-3-methylimidazolium chloride and dimethylsulfoxide ([C4mim] Cl/DMSO) to dissolve the cellulose, though in the related studies the BMP is analyzed in mesophilic conditions only. The BMP values obtained under these conditions are moderate, and generally much lower than the values obtained in the present study (Gao et al., $2013 \mathrm{~b})$. There is very limited information regarding the use of [C2C1Im] [OAc] for the improvement of BMP of lignocellulosic waste. A previous work analyzed the BMP of corn stover and 
TABLE 3 | State-of-the-art of best results on the pre-treatment of lignocellulosic waste by organic solvents and ILs and subsequent anaerobic digestion.

\begin{tabular}{|c|c|c|c|c|c|c|c|c|}
\hline Solvent system* & Conditions & $\begin{array}{l}\text { Lignocellulosic } \\
\text { material }\end{array}$ & $\mathrm{T}\left({ }^{\circ} \mathrm{C}\right)$ & $\begin{array}{c}\text { I/S } \\
\text { ratio** }\end{array}$ & $t(d)$ & $\begin{array}{c}\text { BMP } \\
\left.\text { (L CH } \mathrm{CH}_{4} / \mathrm{Kg} \mathrm{TS}\right)\end{array}$ & $\begin{array}{c}\% \\
\text { Improvement }\end{array}$ & References \\
\hline \multirow[t]{3}{*}{ NMMO } & $120^{\circ} \mathrm{C}, 3 \mathrm{~h}$ & Rice straw & 37 & $2: 1$ & 40 & 314 & 81 & $\begin{array}{l}\text { Mancini et al., } \\
2016\end{array}$ \\
\hline & & Cocoa shell & & & & 216 & 0 & \\
\hline & & Hazelnut skin & & & & 203 & 14 & \\
\hline \multirow[t]{2}{*}{ NMMO } & $120^{\circ} \mathrm{C}, 15 \mathrm{~h}$ & Straw fraction of cattle manure & 55 & NS & 52 & 290 & 53 & $\begin{array}{l}\text { Aslanzadeh et al., } \\
2011\end{array}$ \\
\hline & & Straw fraction of horse manure & & & 52 & 333 & 51 & \\
\hline \multirow[t]{3}{*}{ NMMO } & $130^{\circ} \mathrm{C}, 15 \mathrm{~h}$ & Spruce & 55 & $2: 1$ & 42 & 359 & 272 & $\begin{array}{l}\text { Teghammar et al., } \\
2012\end{array}$ \\
\hline & & Triticale straw & & & & 299 & 630 & \\
\hline & $130^{\circ} \mathrm{C}, 1 \mathrm{~h}$ & Rice straw & & & & 185 & 583 & \\
\hline NMMO & $120^{\circ} \mathrm{C}, 3 \mathrm{~h}$ & Oil palm empty fruit bunch & 55 & $2.7: 1$ & 50 & 347 & 48 & $\begin{array}{l}\text { Purwandari et al., } \\
2013\end{array}$ \\
\hline \multirow[t]{2}{*}{ NMMO } & $90^{\circ} \mathrm{C}, 7 \mathrm{~h}$ & Barley straw & 55 & NS & 45 & 189 & 92 & Kabir et al., 2014 \\
\hline & $90^{\circ} \mathrm{C}, 30 \mathrm{~h}$ & Forest residues & 55 & & 45 & 128 & 88 & \\
\hline [C4mim]Cl/DMSO & $120^{\circ} \mathrm{C}, 2 \mathrm{~h}$ & Water hyacinth & 35 & NS & 30 & 158.1 & 98 & Gao et al., 2013a \\
\hline \multirow[t]{4}{*}{ [C4mim]Cl/DMSO } & $120^{\circ} \mathrm{C}, 2 \mathrm{~h}$ & Water hyacinth & 35 & NS & 30 & 80 & 64 & Gao et al., 2013b \\
\hline & & Rice straw & & & & 129 & 70 & \\
\hline & & Mango leaves & & & & 68 & 65 & \\
\hline & & Spruce & & & & 117 & 66 & \\
\hline \multirow[t]{3}{*}{ [C2C1Im][OAc] } & $100^{\circ} \mathrm{C}, 3 \mathrm{~h}$ & Corn stover & 37 & $2.4: 1$ & 120 & 322 & 19 & Papa et al., 2015 \\
\hline & & Switchgrass & & & & 290 & 14 & \\
\hline & $90^{\circ} \mathrm{C}, 30 \mathrm{~h}$ & Forest residues & 55 & & 45 & 128 & 88 & \\
\hline \multirow[t]{6}{*}{ [C2C1Im][OAc] } & $105^{\circ} \mathrm{C}, 7 \mathrm{~h}$ & Barley straw & 37 & $2: 1$ & 35 & 412 & 80 & This work \\
\hline & & & 37 & $1: 1$ & & 388 & 88 & \\
\hline & & & 37 & $1: 2$ & & 257 & 38 & \\
\hline & & & 55 & $2: 1$ & & 364 & 28 & \\
\hline & & & 55 & $1: 1$ & & 293 & 22 & \\
\hline & & & 55 & $1: 2$ & & 274 & 10 & \\
\hline
\end{tabular}

${ }^{\star} N M M O, N$-Methylmorpholine N-oxide, ${ }^{\star \star} / n o c u l u m$ to Substrate ratio in $d w$ basis.

switchgrass upon dissolution with [C2C1Im][OAc], obtaining moderate improvement of the BMP with respect to untreated biomass. However, this study used very extended digestion time (120 day), and therefore the effect of the pre-treatment on the kinetics of the $\mathrm{AD}$ process was hidden, and only a small increment of methane potential was observed presumably due to the improvement of the biodegradability of the feedstock (Papa et al., 2015). Despite the promising results shown in the literature, there is still strong criticism on the use of ILs for BMP improvement, as is further described below.

\section{Drawbacks and Potentials of Lignocellulosic IL Pre-treatment}

Main drawbacks of the use of ILs are related with the limited knowledge on the effect of the dissolution process on the $\mathrm{AD}$ performance and a general lack of optimization procedures. However, these drawbacks can be overcome through dedicated optimization and process tuning.

The lack of nutrients can hinder the AD process of IL-pretreated lignocellulosic feedstock in a long-time frame due to the elemental composition of this feedstock, which mainly lacks a $\mathrm{N}$ source to sustain bacterial growth. As an alternative to chemical pre-treatments, co-digestion of this biomass with $\mathrm{N}$ rich waste (as manure) would provide $\mathrm{N}$ and trace elements to the $\mathrm{AD}$ process (Mao et al., 2017). However, the use of highly alkaline co-substrates can derive in problems due to high $\mathrm{pH}$ values, and can maximize the toxic effect of free ammonia, especially at high $\mathrm{NH}_{4}^{+}$concentrations (Hansen et al., 1998). In contrast, as shown recently, direct chemical pre-treatment of lignocellulosic biomass seems to be more effective than addition of extra trace elements (Mancini et al., 2018). This is due to the low nutrients requirements of methanogens in comparison with the requirements of hydrolytic and fermentative bacteria. The chemical pre-treatments destroy the structure of lignocellulosic material, solubilize the biomass and reduce the need for high nutrients-dependent hydrolytic and fermentative processes. This in turn decreases the number of steps needed to transform the organic carbon into methane by methanogens, and therefore increases the methane potential of the lignocellulosic feedstock.

Another potential drawback is the need for cleaning the lignocellulosic feedstock after the pre-treatment to avoid residual ILs in the structure, as there are clear evidences indicating that these compounds are highly inhibitory to methanogenic consortia ( $\mathrm{Li}$ and $\mathrm{Xu}, 2017$; Li et al., 2017), even to cellulose hydrolyzers (Zhu et al., 2013). However, recent advances have found that it is possible to enrich a consortium that is resistant to the toxicity of the ILs on the cellulose activity (Tantayotai et al., 2016), strongly indicating that an AD consortia can be adapted to 
IL-bearing lignocellulosic waste after long periods of continuous adaptation. For example, UASB-type reactors can be used, where the hydrolytic bacteria are commonly found in the external layers of the anaerobic granules, and can act as a protective barrier against the toxicity of residual ILs to more sensitive methanogens.

In any case, all these drawbacks are related to an obvious lack of optimization procedures, as this technology is still in its infancy. More studies are needed for knowing the real effect of the IL pre-treatment on the $\mathrm{AD}$ of lignocellulosic materials, as there is very limited information regarding continuous treatment of these materials by $\mathrm{AD}$ processes. A recent study showed the continuous treatment of raw and pre-treated with NMMO lignocellulosic waste textiles by a two-stage AnSBRUASB anaerobic process, where the pre-treatment achieved almost double methane production compared to the process using raw waste (400 vs. $200 \mathrm{~L} \mathrm{CH} 4 / \mathrm{kg}$ VS d) (Jeihanipour et al., 2013). This reflects the potential of this promising technology, though field demonstration is still needed.

\section{Kinetics of the Anaerobic Digestion Process}

A kinetic analysis was performed on the BMP tests data. The parameters estimation for a first order model was carried out and the values and 95\% confidence intervals are depicted in Figure 6, along with the $95 \%$ confidence surfaces of the $k_{H} / B_{0}$ intercept. The first order model accurately predicts the BMP profiles. Simulation curves shown in Figure 5 indicates that the goodness of fitting is acceptable $\left(\mathrm{R}^{2}\right.$ higher than 0.95 in all cases). In addition, relatively low $95 \%$ confidence intervals for the parameters values are estimated. Therefore, this simplified model and the parameters values can be used for the analysis and comparison of the $\mathrm{AD}$ performance in the different BMP tested, as has been previously suggested (Angelidaki et al., 2009).

The kinetic analysis confirmed that the IL treatment only increased slightly the methane potential in thermophilic conditions (Figure 6A). A $B_{0}$ value of $379 \pm 16 \mathrm{LCH}_{4} / \mathrm{kgTS}$ for a I/S of 2:1 was obtained after IL pre-treatment, which is higher than other values obtained for energy crops at thermophilic conditions (Meng et al., 2016).

However, as previously mentioned, the hydrolysis rate considerable decreased, presumably due to the solubilisation of polysaccharides that promoted the growth of thermophilic fermentative bacteria, decreasing the $\mathrm{pH}$. Indeed, the soluble $\mathrm{COD}$ at the end of the experiments resulted from the feedstock was much higher with the IL-treated feedstocks: 369 and 296 vs. 185 and $98 \mathrm{mgCOD} \mathrm{L}^{-1}$ at I/S of 2:1 and 1:1 for pre-treated and fresh biomass, respectively. Relatively low $\mathrm{pH}(<7)$ was generally observed after the thermophilic treatments, being lower than 6 (5.8) in the case of the I/S ratio of $1: 2$, which concurs with the lowest $B_{0}$ values calculated at this I/S ratio, regardless of the pre-treatment.

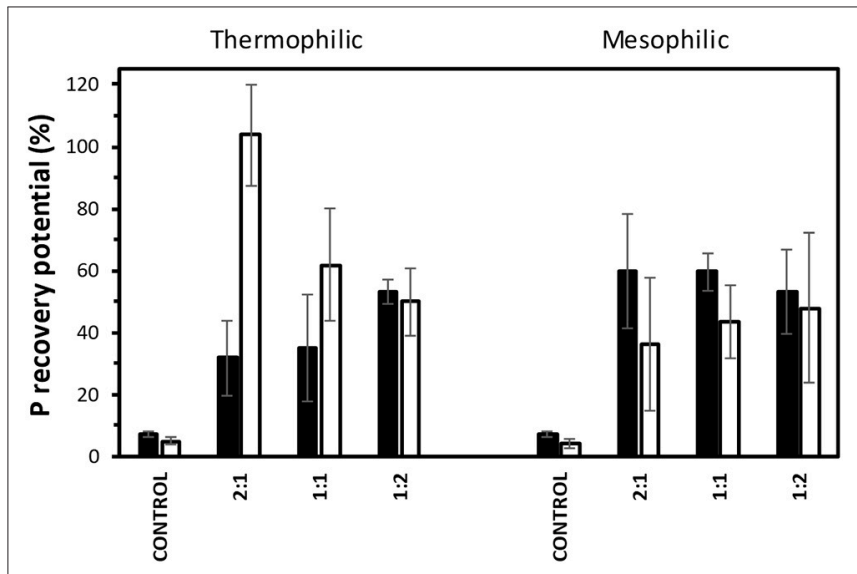

FIGURE 7 | Phosphorus recovery potential upon anaerobic digestion of fresh (black bars) and IL-pre-treated (white bars) barley straw in thermophilic and mesophilic conditions at different I/S ratios. Error bars are $95 \%$ confidence intervals.
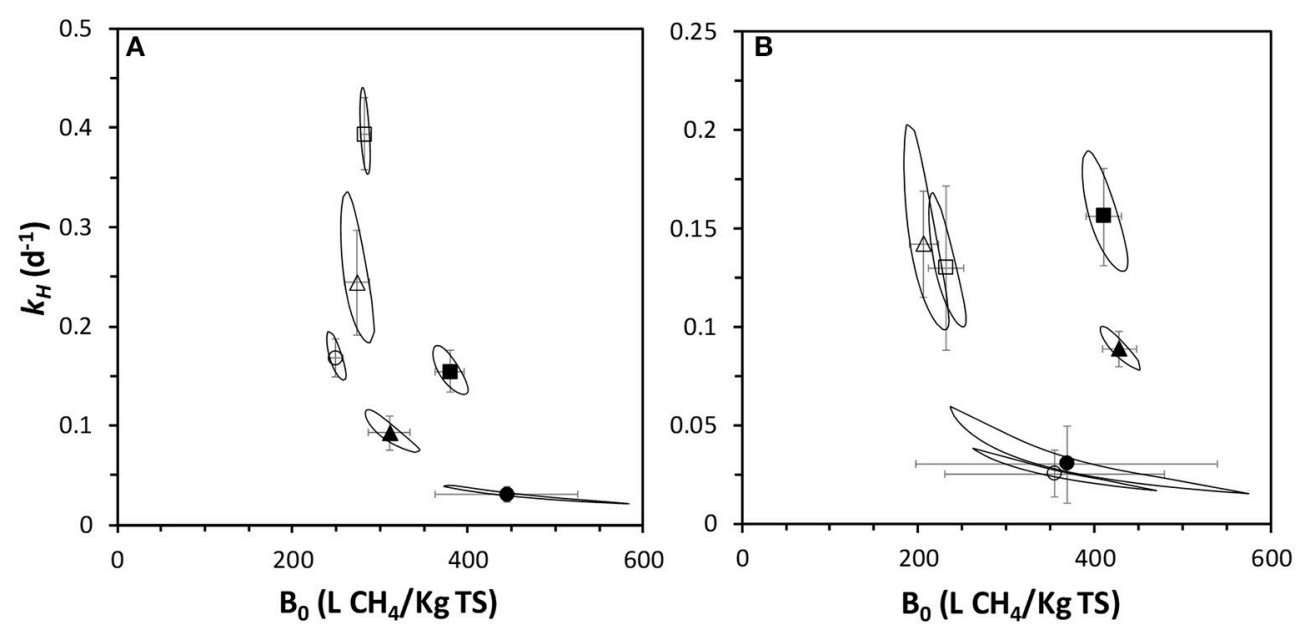

FIGURE 6 | Kinetic parameters of thermophilic (A) and mesophilic (B) BMP profiles of fresh (open symbols) and pre-treated (closed symbols) at I/S ratio of 2:1 (squares), 1:1 (triangles) and 1:2 (circles). Error bars are $95 \%$ confidence intervals from parameter estimation. Continuous lines are $95 \%$ confidence regions for $k_{H} / B_{0}$ intercept. 
Kinetic parameters and statistical analysis of mesophilic BMPs are depicted in Figure 6B. This analysis corroborates that the IL pre-treatment increased considerably the methane potential of this feedstock. $B_{0}$ values of $410 \pm 20$ and $418 \pm 19 \mathrm{LCH}_{4} / \mathrm{kgTS}$ at I/S of 2:1 and 1:1 after IL pre-treatment contrasted positively with those values obtained with the fresh sludge, $282 \pm 17$ and $240 \pm 40 \mathrm{LCH}_{4} / \mathrm{KgTS}$, respectively.

In addition, there were no statistical differences in the $k_{H}$ at I/S of $2: 1$ and $1: 1$, remaining around $0.10-0.151 / \mathrm{d}$, which concurs with typical values obtained in energy crops (Meng et al., 2016). The I/S of 1:2 considerably decreased the $k_{H}$ values, which may be due to biomass transfer problems due to bad mixing or inhibition by organic acids accumulation, as has been claimed previously in BMP standardization procedures (Holliger et al., 2016).

\section{Nutrients Recovery Potential}

As commented before, the release of nutrients upon the $\mathrm{AD}$ process is an opportunity to regain these compounds to be used furtherly in industrial or agroforestry applications, especially $\mathrm{N}$ and $\mathrm{P}$. $\mathrm{N}$ recovery seems to be unreliable due to the low $\mathrm{N}$ content of the biomass. $\mathrm{P}$ recovery, however, sounds promising and can be a driver to an agroforestry-based biorefinery process development. Figure 7 shows the $\mathrm{P}$ recovery potential from the digestate after $\mathrm{AD}$ between the fresh and pre-treated biomass samples. In general, there are clear differences on the P recovery potential in function of the thermal conditions of the $\mathrm{AD}$ treatment and their relationship with the I/S ratio. However, these differences are less significant for the mesophilic conditions in both fresh and IL-pre-treated biomass samples regarding the $\mathrm{I} / \mathrm{S}$ ratio. The $\mathrm{P}$ recovery potential of the fresh biomass upon $\mathrm{AD}$ remains around $50-55 \%$, whereas this value slightly reduced down to around $35-40 \%$ in the case of the IL-pre-treated biomass, irrespective to the I/S ratios. In thermophilic conditions, both the I/S ratio and the pre-treatment clearly modify the $\mathrm{P}$ recovery potential. Low I/S ratios seem to enhance the $\mathrm{P}$ release for the fresh biomass, since the $\mathrm{P}$ recovery potential is increased from around $30 \%$ at a $\mathrm{I} / \mathrm{S}$ ratio of $2: 1$ to around $50 \%$ at a $\mathrm{I} / \mathrm{S}$ ratio of 1:2. In contrast, and surprisingly, the pre-treated biomass displayed the opposite behavior. At I/S ratio of 2:1 the P recovery potential is very high (close to the theoretical 100\%), whereas these values decreased down to around $50 \%$ for an I/S ratio of $1: 2$. In summary, it can be concluded that the best conditions for maximizing the $\mathrm{P}$ recovery potential are pretreating the biomass with ILs and applying thermophilic digestion at high I/S ratios.

\section{Resources Recovery From Barley Straw}

The classical concept about $\mathrm{AD}$ as a driver to resource recovery is changing rapidly. It is well stablished that the $\mathrm{AD}$ process is a mature and reliable way of extracting and leveraging the chemical

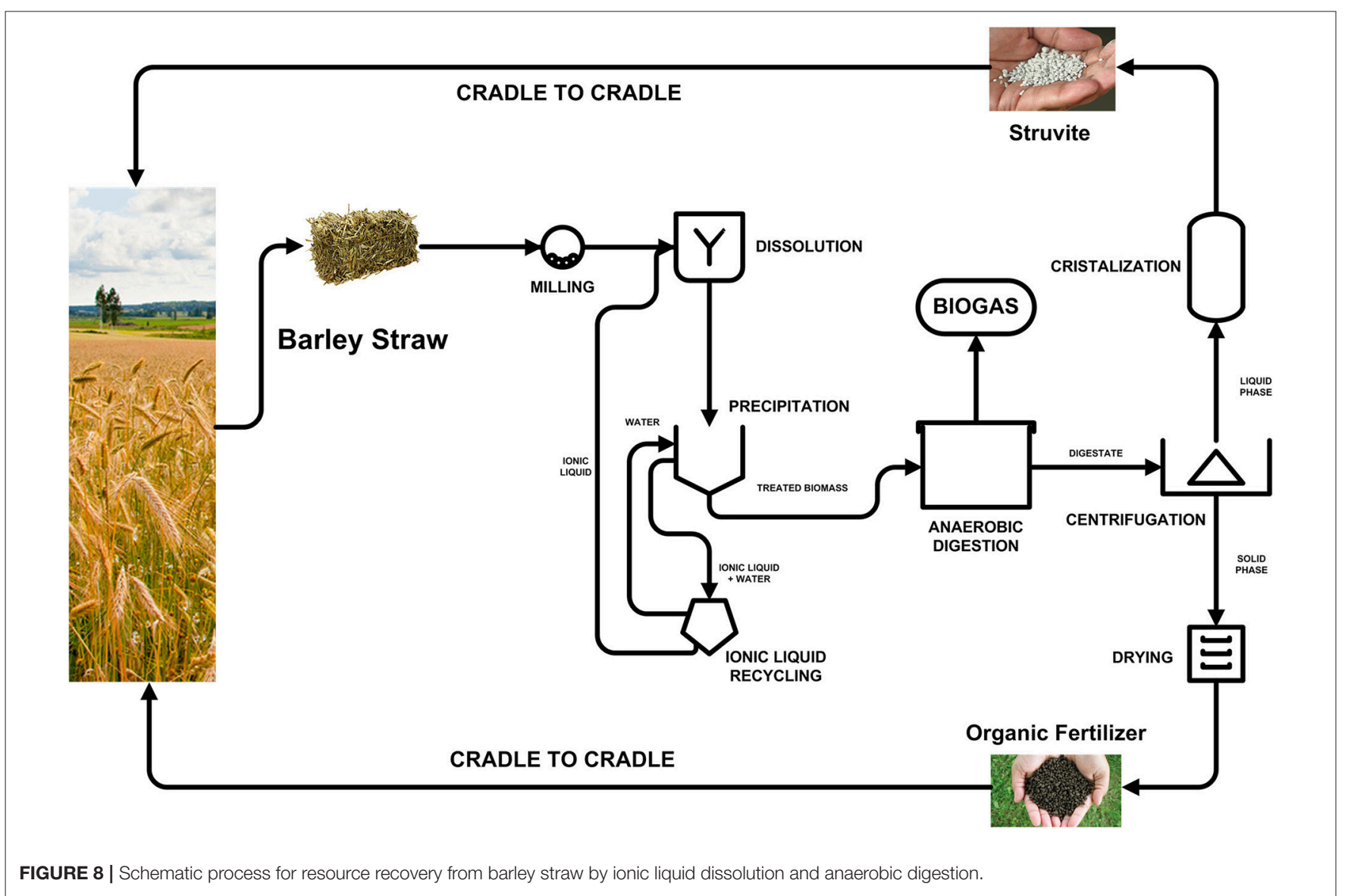


energy contained in the residual waste, irrespective to its origin (Puyol et al., 2017). AD has been exploited as an alternative and sustainable way of obtaining energy from renewable sources. Energy crops are among the most typical biomass sources to be used for this purpose, though this has ethical connotations in which second-generation biofuels are direct competitors of foodbased agriculture (Tenenbaum, 2008). However, the AD concept has been upgraded to deal with the production of energy from biomass of residual origin, thereby avoiding the competition with food production. The direct production of energy from barley straw is a direct example of this concept.

Nevertheless, novel concepts for resource recovery are dealing with the paradigm of the circular economy, where the residues from the productive system must be completely re-introduced in the market as raw matter (Puyol et al., 2017). In the agroforestry industry, the energy recovery is a necessary resource but is lowcost, and it cannot solve the problem of fertilizers depletion. In this sense, it is necessary to re-conceptualize the use of the $\mathrm{AD}$ for agroforestry waste treatment by proposing new ways of recovering high value-added resources from this waste, notably sustainable fertilizers (Batstone and Virdis, 2014).

Based on the results obtained in this work, we propose the use of the $\mathrm{AD}$ process as a core part of a novel strategy of energy and $\mathrm{P}$ recovery from the barley straw, in particular. This biorefinery concept is summarized in Figure 8. The barley straw is collected from the farm activities and milled to reduce and homogenize its size. Thereby, IL-based pre-treatment is applied to the straw to deconstruct lignocellulosic matter. The addition of water leads to the precipitation of the treated biomass, which is furtherly separated from the IL. The IL is then recovered and reused in a circular way. The treated biomass is anaerobically digested in thermal conditions at high sludge retention times to have a high I/S ratio (SRT above 35 day). Thereby, a value close to $400 \mathrm{~L} \mathrm{CH}_{4} / \mathrm{kg}$ TS has been achieved and, most interestingly, the $\mathrm{P}$ contained in the biomass was almost completely released and mobilized into the digestate (as has been demonstrated in this work). Commercial technologies can be applied to recover the soluble $\mathrm{P}$ as struvite from the liquid fraction of the digestate. The solid fraction of the digestate can be directly converted into organic fertilizer by air-drying. Both resources and the water excess can be re-introduced into the market and serve as fertilizers for sustainable and bio-economical agriculture, which close the circle.

The key part of the concept, due to reactants consumption and energy needs, is the IL pre-treatment. As the technology is still in its infancy, with an optimistic technological readiness level of 3, the economics of the process can only be derived from theoretical analyses or lab-scales mass and energy balances approximations. As pointed out previously, the aim is to reduce the costs below $\$ 1 / \mathrm{kg}$ IL, with $>97 \%$ of IL recovery and $>90 \%$ of waste heat recovery (Baral and Shah, 2016). These are very optimistic considerations, and the technology requires further development. However, techno-economic assessments still do not include the $\mathrm{P}$ recovery, and decrease of $\mathrm{C}$ footprint due to mild conditions (Segura et al., 2016). There are also other potential IL alternatives that may reduce considerably the IL costs. George et al. (2015) used the low cost IL triethylammonium hydrogen sulfate as an alternative to the commercial 1-ethyl-3methylimidazolium acetate, achieving around $75 \%$ efficiency of the commercial IL, demonstrating that some ILs can compete with the cheapest pretreatment chemicals, such as ammonia, in terms of effectiveness and process cost. A further scale-up of the technology using this low-cost IL has been tested in simulation, and results based on a continuous lab-scale process demonstrated that is possible to reduce the IL costs below $\$ 1 / \mathrm{kg}$ IL with a $>97 \%$ IL recovery. However, heat recovery is not contemplated in that simulation (Brandt-Talbot et al., 2017). In the concept proposed here the $\mathrm{AD}$ process under thermophilic conditions is a high heat-demanding process. The optimization of the heat recovery should be driven toward making the most of the heat excess during the $\mathrm{AD}$ process.

\section{CONCLUSIONS}

The effect of pre-treatment of lignocellulosic feedstock (barley straw) by the IL [C2C1Im][OAc] on the bioenergy (biogas) and $\mathrm{P}$ recovery potentials has been analyzed through dedicated BMP tests and mass balances analysis. Main outcomes of this work are listed below:

- Deconstruction of lignocellulosic feedstock by IL causes an increase in the BMP, achieving values of 412 and $364 \mathrm{~L} \mathrm{CH}_{4} / \mathrm{kg}$ TS for a I/S ratio of 2:1 in mesophilic and thermophilic conditions, respectively.

- High solubilization of the feedstock by IL-pretreatment produces inhibition of the methanogenesis rate due to excess of the acidogenesis process, especially at thermophilic conditions. This can be controlled by applying an adequate I/S ratio.

- The IL-pretreatment increases considerably the solids destruction and also enhances the $\mathrm{P}$ recovery potential, especially upon the thermophilic $\mathrm{AD}$, where $\mathrm{P}$ solubilization is close to the theoretical $100 \% \mathrm{P}$ balance.

\section{AUTHOR CONTRIBUTIONS}

DP designed the experiments and redacted the manuscript. JC-M designed the experiments and reviewed the manuscript. BP, ML$\mathrm{S}$, and SM performed the experimental analyses. JF, FM, and JM critically reviewed the manuscript. DP and JC-M are both corresponding authors.

\section{ACKNOWLEDGMENTS}

The authors acknowledge financial support from Comunidad de Madrid (Spain) (RESTOENE-2-CM S2013/MAE-2882 and REMTAVARES-CM S2013/MAE-2716 projects) and ML-S acknowledges the supporting of European Social Fund and Comunidad de Madrid for her contract. 


\section{REFERENCES}

Agbor, V. B., Cicek, N., Sparling, R., Berlin, A., and Levin, D. B. (2011). Biomass pretreatment: fundamentals toward application. Biotechnol. Adv. 29, 675-685. doi: 10.1016/j.biotechadv.2011.05.005

Angelidaki, I., Alves, M., Bolzonella, D., Borzacconi, L., Campos, J. L., Guwy, A. J. et al. (2009). Defining the biomethane potential (BMP) of solid organic wastes and energy crops: a proposed protocol for batch assays. Water Sci. Technol. 59, 927-934. doi: 10.2166/wst.2009.040

Aslanzadeh, S., Taherzadeh, M. J., and Horváth, I. S. (2011). Pretreatment of straw fraction of manure for improved biogas production. BioResources 6, 5193-5205.

Baral, N. R., and Shah, A. (2016). Techno-economic analysis of cellulose dissolving ionic liquid pretreatment of lignocellulosic biomass for fermentable sugars production. Biofuels Bioproducts Biorefining 10, 70-88. doi: 10.1002/bbb.1622

Batstone, D. J., and Virdis, B. (2014). The role of anaerobic digestion in the emerging energy economy. Curr. Opin. Biotechnol. 27, 142-149. doi: 10.1016/j.copbio.2014.01.013

Brandt-Talbot, A., Gschwend, F. J., Fennell, P. S., Lammens, T. M., Tan, B., Weale, J., et al. (2017). An economically viable ionic liquid for the fractionation of lignocellulosic biomass. Green Chem. 19, 3078-3102. doi: 10.1039/C7GC00705A

Cheng, G., Varanasi, P., Li, C., Liu, H., Melnichenko, Y. B., Simmons, B. A., et al. (2011). Transition of cellulose crystalline structure and surface morphology of biomass as a function of ionic liquid pretreatment and its relation to enzymatic hydrolysis. Biomacromolecules 12, 933-941. doi: 10.1021/bm101240z

Cordell, D., Drangert, J.-O., and White, S. (2009). The story of phosphorus: global food security and food for thought. Global Environ. Change 19, 292-305. doi: 10.1016/j.gloenvcha.2008.10.009

Cordell, D., Rosemarin, A., Schröder, J. J., and Smit, A. L. (2011). Towards global phosphorus security: a systems framework for phosphorus recovery and reuse options. Chemosphere 84, 747-758. doi: 10.1016/j.chemosphere.2011.02.032

Federation, W. E., and Association, A. P. H. (2005). Standard Methods for the Examination of Water and Wastewater.: Washington, DC: American Public Health Association (APHA).

Franke-Whittle, I. H., Walter, A., Ebner, C., and Insam, H. (2014). Investigation into the effect of high concentrations of volatile fatty acids in anaerobic digestion on methanogenic communities. Waste Manage. 34, 2080-2089. doi: 10.1016/j.wasman.2014.07.020

Galinski, M., Lewandowski, A., and Stepniak, I. (2006). Ionic liquids as electrolytes. Electrochim. Acta 51, 5567-5580. doi: 10.1016/j.electacta.2006.03.016

Gao, J., Chen, L., Yan, Z., and Wang, L. (2013a). Effect of ionic liquid pretreatment on the composition, structure and biogas production of water hyacinth (Eichhornia crassipes). Bioresour. Technol. 132, 361-364. doi: 10.1016/j.biortech.2012.10.136

Gao, J., Chen, L., Yuan, K., Huang, H., and Yan, Z. (2013b). Ionic liquid pretreatment to enhance the anaerobic digestion of lignocellulosic biomass. Bioresour. Technol. 150, 352-358. doi: 10.1016/j.biortech.2013.10.026

George, A., Brandt, A., Tran, K., Zahari, S. M. S. N.S., Klein-Marcuschamer, D., Sun, N., et al. (2015). Design of low-cost ionic liquids for lignocellulosic biomass pretreatment. Green Chem. 17, 1728-1734. doi: 10.1039/C4GC 01208A

Ghosh, S., Henry, M. P., Sajjad, A., Mensinger, M.C, and Arora, J. L. (2000). Pilot-scale gasification of municipal solid wastes by high-rate and two-phase anaerobic digestion (TPAD). Water Sci. Technol. 41, 101-110. doi: 10.2166/wst.2000.0061

Hansen, K. H., Angelidaki, I., and Ahring, B. K. (1998). Anaerobic digestion of swine manure: inhibition by ammonia. Water Res. 32, 5-12. doi: 10.1016/S0043-1354(97)00201-7

Heilmann, S. M., Molde, J. S., Timler, J. G., Wood, B. M., Mikula, A. L., Vozhdayev, G. V., et al. (2014). Phosphorus reclamation through hydrothermal carbonization of animal manures. Environ. Sci. Technol. 48, 10323-10329. doi: $10.1021 / \mathrm{es} 501872 \mathrm{k}$

Hendriks, A. T. W. M., and Zeeman, G. (2009). Pretreatments to enhance the digestibility of lignocellulosic biomass. Bioresour. Technol. 100, 10-18. doi: 10.1016/j.biortech.2008.05.027

Holliger, C., Alves, M., Andrade, D., Angelidaki, I., Astals, S., Baier, U., et al. (2016). Towards a standardization of biomethane potential tests. Water Sci. Technol. 74, 2515-2522. doi: 10.2166/wst.2016.336
Jeihanipour, A., Aslanzadeh, S., Rajendran, K., Balasubramanian, G., and Taherzadeh, M. J. (2013). High-rate biogas production from waste textiles using a two-stage process. Renew. Energy 52, 128-135. doi: $10.1016 /$ j.renene.2012.10.042

Jönsson, L. J., and Martín, C. (2016). Pretreatment of lignocellulose: formation of inhibitory by-products and strategies for minimizing their effects. Bioresour. Technol. 199, 103-112. doi: 10.1016/j.biortech.2015.10.009

Kabir, M. M., Niklasson, C., Taherzadeh, M. J., and Horváth, I. S. (2014). Biogas production from lignocelluloses by $\mathrm{N}$-methylmorpholine-N-oxide (NMMO) pretreatment: effects of recovery and reuse of NMMO. Bioresour. Technol. 161, 446-450. doi: 10.1016/j.biortech.2014.03.107

Kassaye, S., Pant, K. K., and Jain, S. (2017). Hydrolysis of cellulosic bamboo biomass into reducing sugars via a combined alkaline solution and ionic liquid pretreament steps. Renew. Energy 104, 177-184. doi: 10.1016/j.renene.2016.12.033

Kim, M., Gomec, C. Y., Ahn, Y., and Speece, R. E. (2003). Hydrolysis and acidogenesis of particulate organic material in mesophilic and thermophilic anaerobic digestion. Environ. Technol. 24, 1183-1190. doi: $10.1080 / 09593330309385659$

Lara-Serrano, M., Sáez Angulo, F., Negro, M. J., Morales-delaRosa, S., CamposMartin, J. M., and Fierro, J. L. G. (2018). Second-Generation Bioethanol Production Combining Simultaneous Fermentation and Saccharification of IL-Pretreated Barley Straw. ACS Sustainable Chem. Eng 6, 7086-7095. doi: 10.1021/acssuschemeng.8b00953

Li, W., and Xu, G. (2017). Enhancement of anaerobic digestion of grass by pretreatment with imidazolium-based ionic liquids. Environ. Technol. 38, 1843-1851. doi: 10.1080/09593330.2016.1238963

Li, X., Schwede, S., Li, H., Yu, X., Yu, Z., and Zhu, K. (2017). Toxicity of ionic liquid on anaerobic digestion. Energy Procedia 142, 938-942. doi: 10.1016/j.egypro.2017.12.150

Mancini, G., Papirio, S., Lens, P. N., and Esposito, G. (2016). Effect of Nmethylmorpholine-N-oxide pretreatment on biogas production from rice straw, cocoa shell, and hazelnut skin. Environ. Eng. Sci. 33, 843-850. doi: $10.1089 /$ ees.2016.0138

Mancini, G., Papirio, S., Riccardelli, G., Lens, P. N. L., and Esposito, G. (2018). Trace elements dosing and alkaline pretreatment in the anaerobic digestion of rice straw. Bioresour. Technol. 247, 897-903. doi: 10.1016/j.biortech.2017.10.001

Mao, C., Zhang, T., Wang, X., Feng, Y., Ren, G., and Yang, G. (2017). Process performance and methane production optimizing of anaerobic co-digestion of swine manure and corn straw. Sci. Rep. 7:9379. doi: 10.1038/s41598-017-09977-6

Mehta, C. M., and Batstone, D. J. (2013). Nutrient solubilization and its availability following anaerobic digestion. Water Sci. Technol. 67, 756-763. doi: $10.2166 /$ wst.2012.622

Meng, Y., Jost, C., Mumme, J., Wang, K., and Linke, B. (2016). An analysis of single and two stage, mesophilic and thermophilic high rate systems for anaerobic digestion of corn stalk. Chem. Eng. J. 288, 79-86. doi: 10.1016/j.cej.2015.11.072

Morales-delaRosa, S., Campos-Martin, J. M., and Fierro, J. L. (2014a). Complete chemical hydrolysis of cellulose into fermentable sugars through ionic liquids and antisolvent pretreatments. ChemSusChem 7, 3467-3475. doi: $10.1002 /$ cssc. 201402466

Morales-delaRosa, S., Campos-Martin, J. M., and Fierro, J. L. G. (2014b). Optimization of the process of chemical hydrolysis of cellulose to glucose. Cellulose 21, 2397-2407. doi: 10.1007/s10570-014-0280-9

Morales-delaRosa, S., Campos-Martin, J. M., and Fierro, J. L. G. (2018). Chemical hydrolysis of cellulose into fermentable sugars through ionic liquids and antisolvent pretreatments using heterogeneous catalysts. Catalysis Today 302, 87-93. doi: 10.1016/j.cattod.2017.08.033

Morales-delaRosa, S., García Fierro, J. L., and Campos-Martín, J. M. (2015). Method for the Hydrolysis of Lignocellulosic Biomass.

Mosier, N., Wyman, C., Dale, B., Elander, R., Lee, Y. Y., Holtzapple, M., et al. (2005). Features of promising technologies for pretreatment of lignocellulosic biomass. Bioresour. Technol. 96, 673-686. doi: 10.1016/j.biortech.2004.06.025

Papa, G., Rodriguez, S., George, A., Schievano, A., Orzi, V., Sale, K. L., et al. (2015). Comparison of different pretreatments for the production of bioethanol and biomethane from corn stover and switchgrass. Bioresour. Technol. 183, 101-110. doi: 10.1016/j.biortech.2015.01.121 
Purwandari, F. A., Sanjaya, A. P., Millati, R., Cahyanto, M. N., Horváth, I. S., Niklasson, C., et al. (2013). Pretreatment of oil palm empty fruit bunch (OPEFB) by $\mathrm{N}$-methylmorpholine-N-oxide (NMMO) for biogas production: structural changes and digestion improvement. Bioresour. Technol. 128, 461-466. doi: 10.1016/j.biortech.2012.10.088

Puyol, D., Batstone, D. J., Hülsen, T., Astals, S., Peces, M., and Krömer, J. O. (2017). Resource recovery from wastewater by biological technologies: opportunities, challenges, and prospects. Front. Microbiol. 7:2016. doi: $10.3389 /$ fmicb. 2016.02106

Sawatdeenarunat, C., Surendra, K. C., Takara, D., Oechsner, H., and Khanal, S. K. (2015). Anaerobic digestion of lignocellulosic biomass: challenges and opportunities. Bioresour. Technol. 178, 178-186. doi: 10.1016/j.biortech.2014.09.103

Segura, Y., Puyol, D., Ballesteros, L., Martínez, F., and Melero, J. (2016). Wastewater sludges pretreated by different oxidation systems at mild conditions to promote the biogas formation in anaerobic processes. Environ. Sci. Pollut. Res. 23, 24393-24401. doi: 10.1007/s11356-016-7535-y

Sharpley, A. (2016). Managing agricultural phosphorus to minimize water quality impacts. Sci. Agric. 73, 1-8. doi: 10.1590/0103-9016-2015-0107

Shi, J., Thompson, V. S., Yancey, N. A., Stavila, V., Simmons, B. A., and Singh, S. (2013). Impact of mixed feedstocks and feedstock densification on ionic liquid pretreatment efficiency. Biofuels 4, 63-72. doi: 10.4155/bfs.12.82

Sims, R. (2003). Biomass and Resources Bioenergy Options for a Cleaner Environment in Developed and Developing Countries. London: Elsevier Science.

Sluiter, J. B., Ruiz, R. O., Scarlata, C. J., Sluiter, A. D., and Templeton, D. W. (2010). Compositional analysis of lignocellulosic feedstocks. 1. Review and description of methods. J. Agric. Food Chem. 58, 9043-9053. doi: 10.1021/jf1008023

Tantayotai, P., Rachmontree, P., Rodiahwati, W., Rattanaporn, K., and Sriariyanun, M. (2016). Production of ionic liquid-tolerant cellulase produced by microbial consortium and its application in biofuel production. Energy Procedia 100, 155-159. doi: 10.1016/j.egypro.2016.10.158

Tarayre, C., De Clercq, L., Charlier, R., Michels, E., Meers, E., Camargo-Valero, M., et al. (2016). New perspectives for the design of sustainable bioprocesses for phosphorus recovery from waste. Bioresour. Technol. 206, 264-274. doi: 10.1016/j.biortech.2016.01.091

Teghammar, A., Karimi, K., Sárvári Horváth, I., and Taherzadeh, M. J. (2012). Enhanced biogas production from rice straw, triticale straw and softwood spruce by NMMO pretreatment. Biomass Bioenergy 36, 116-120. doi: 10.1016/j.biombioe.2011.10.019

Tenenbaum, D. J. (2008). Food vs. fuel: diversion of crops could cause more hunger. Environ. Health Perspect. 116, A254-A257. doi: 10.1289/ehp.116-a254

Vassilev, S. V., Baxter, D., Andersen, L. K., and Vassileva, C. G. (2010). An overview of the chemical composition of biomass. Fuel 89, 913-933. doi: 10.1016/j.fuel.2009.10.022

Wilkie, A. C. (2008). Biomethane from biomass, biowaste and biofuels. Bioenergy Chapter 16, 197-205. doi: 10.1128/9781555815547.ch16

Zheng, Y., Zhao, J., Xu, F., and Li, Y. (2014). Pretreatment of lignocellulosic biomass for enhanced biogas production. Prog. Energy Combust. Sci. 42, 35-53. doi: 10.1016/j.pecs.2014.0 1.001

Zhu, S., Yu, P., Lei, M., Tong, Y., Zheng, L., Zhang, R., et al. (2013). Investigation of the toxicity of the ionic liquid 1-butyl-3-methylimidazolium chloride to Saccharomyces cerevisiae AY93161 for lignocellulosic ethanol production. Polish J. Chemi. Technol. 15, 94-98. doi: 10.2478/pjct-2013-0029

Conflict of Interest Statement: The authors declare that the research was conducted in the absence of any commercial or financial relationships that could be construed as a potential conflict of interest.

Copyright (c) 2018 Padrino, Lara-Serrano, Morales-delaRosa, Campos-Martín, Fierro, Martinez, Melero and Puyol. This is an open-access article distributed under the terms of the Creative Commons Attribution License (CC BY). The use, distribution or reproduction in other forums is permitted, provided the original author(s) and the copyright owner(s) are credited and that the original publication in this journal is cited, in accordance with accepted academic practice. No use, distribution or reproduction is permitted which does not comply with these terms. 